\title{
OBJETOS DE APRENDIZAGEM PARA O ENSINO DE GEOGRAFIA: INTERAÇÃO E ANIMAÇÃO COM SIMULADORES
}

\author{
Franciele Francisca Marmentini Rovani - PPGGEO UFSM - franciele.rovani@yahoo.com.br \\ Gabriela Dambros - PPGGEO UFSM - gabbydambros@yahoo.com.br \\ João Henrique Quoos - PPGGEO UFSM - jhquoos@ gmail.com \\ Roberto Cassol - Prof. Dr. do Departamento de Geociências da UFSM - rtocassol@gmail.com
}

\section{Resumo}

O objetivo deste trabalho constou da elaboração de objetos de aprendizagem para serem aplicados em sala de aula abordando temas e conceitos geográficos, visando contribuir para o processo de ensino e aprendizagem, especialmente da Geografia. Para tanto, utilizou-se os softwares ArcGis 9.3, no módulo ArcMap, o Photoshop e o Flash. Como resultado obteve-se dois simuladores animados e interativos: um de relevo e outro de bacias hidrográficas. De posse destes materiais elaboraram-se algumas sugestões de aplicação dos mesmos com alunos da Educação Básica, de modo a proporcionar a interação dos mesmos com os materiais. Assim, contatou-se que as tecnologias na educação apresentam-se como grandes potenciais para a aprendizagem e integração dos educandos com os temas em estudo.

Palavras-chave: objetos de aprendizagem, ensino, relevo, bacia hidrográfica, geografia

\section{LEARNING OBJECTS FOR THE TEACHING OF GEOGRAPHY: INTERACTION AND ANIMATION WITH SIMULATORS}

\begin{abstract}
The objetive of this work consisted of development of learning objects to be applied in the classroom subjects and geographical concepts, aiming at contributing to the process of teaching and learning, especially Geography. To do so, we used the software ArcGis in module ArcMap 9.3, Photoshop and Flash. As a result we obtained two animated and interactive simulators: a relief and another of drainage basin. Possession of these materials have prepared some suggestions for applying the same with basic education students, with a view to giving the same interaction with the materials. So I contacted that the technologies in education present themselves as great potential for learning and integration of students with the themes under study.
\end{abstract}

Keywords: learning objects, education, relief, drainage basin, geography

\section{INTRODUÇÃO}

Atualmente, estamos vivenciando um período de desenvolvimento tecnológico, que Santos (1994) denominou de período técnico-científico informacional, que requer significativas transformações nos diversos setores da sociedade com o intuito de compreender as relações socio-espaciais cada vez mais complexas. No âmbito educacional, a tecnologia vem ao encontro de novas perspectivas que visam dinamizar o processo ensino-aprendizagem através de instrumentos interativos auxiliares.

Diante desta sociedade tecnológica e informacional, as tecnologias interativas aplicadas na educação, segundo Barros e Júnior (2005, p.74), "permitem ampliar a pluralidade de abordagens, atender a diferentes estilos de aprendizagem e, desta forma, favorecer a aquisição de conhecimentos, competências e habilidades". 
A utilização das Tecnologias de Informação e Comunicação (TICs) na educação, adotando novas metodologias de ensino e aprendizagem, são iniciativas que requerem conhecimentos destas tecnologias e de suas potencialidades como instrumento didático (Giordani, et al., 2008). A partir disso, Moreira e Ulhôa (2009, p.78) consideram importante destacar que "a tecnologia multimídia pode potencializar ou limitar a compreensão de mundo por parte dos alunos, dependendo da maneira que for conduzida nos ambientes de ensino-aprendizagem presencial ou virtual".

De acordo com os PCNs (1998), a incorporação das novas tecnologias só tem sentido se contribuir para a melhoria da qualidade de ensino. Destaca ainda que, somente a presença das tecnologias nas salas de aula não garante mudança na forma de ensinar e aprender. É necessário que professores e alunos construam juntos os conhecimentos por meio de uma prática ativa, crítica e criativa e assim, as tecnologias enriqueçam o ambiente educacional. Deste modo é importante enfatizar que na escola, o professor é o mediador do conhecimento e os alunos estudam e apreendem o espaço de maneiras diferenciadas de acordo com suas capacidades cognitivas. Quando o professor dialoga a teoria, ou seja, o conhecimento científico com os saberes cotidianos, os alunos despertam como sujeitos ativos daquele contexto e permitem desta forma, a construção diferenciada do conhecimento (Bitar; Sousa, 2009).

Neste sentido, destacam-se os objetos de aprendizagem (OAs) que segundo Tarouco, et al. (2003, p. 2) podem ser definidos "como qualquer recurso, suplementar ao processo de aprendizagem, que pode ser reusado para apoiar a aprendizagem". Estes recursos normalmente são arquivos de multimídia e interativos com base educacional, que visam auxiliar os professores em suas práticas pedagógicas, contribuindo para o ensino e a aprendizagem de maneira lúdica e interativa. Assim, os conteúdos e conceitos fundamentais da Geografia podem ser melhor trabalhados por meio das TICs, pois com elas podem ser propostos desafios cognitivos, modificação e enriquecimento progressivo dos esquemas de conhecimento de modo mais significativo, uma vez que permitem o acesso à variadas formas de linguagens e diferentes pontos de vista (Sales, 2009).

Nesta perspectiva, este trabalho teve como objetivo principal desenvolver objetos de aprendizagem lúdicos e interativos relacionados a temas geográficos: relevo e bacias hidrográficas, para serem utilizados nas aulas de Educação Básica. Além disso, objetiva-se integrar a estes recursos noções cartográficas e de espaço. Assim, a interação dos alunos com estes materiais possibilitará desenvolver, com maior eficácia, a compreensão da formação do relevo, bem como da formação das bacias hidrográficas e sua importância para o meio em que vivemos. A representação e visualização deste espaço implicarão no reconhecimento, seja em escala local, regional, nacional ou global, da dinâmica dos fenômenos geográficos permitindo ao aluno uma visão crítica da realidade na qual pertence.

\section{MATERIAIS E MÉTODOS}

Para a elaboração dos objetos de aprendizagem, inicialmente realizou-se uma revisão de conceitos geográficos importantes que posteriormente foram introduzidos neste material por meio de representações. Abordou-se os conceitos de relevo, curvas de nível, bacia hidrográfica, divisor de águas e rio. 
A escolha da representação do relevo, conjunto de formações da superfície do planeta, justifica-se pelo fato de pode ser compreendido e visualizado, de acordo com IBGE (1999), das seguintes maneiras: curvas de nível, perfis topográficos, relevo sombreado, cores hipsométricas, etc. Neste material utilizou-se o conceito de curvas de nível para representação do relevo em que podem ser compreendidas como linhas imaginárias do terreno, em que todos os pontos de referida linha têm a mesma altitude, acima ou abaixo de uma determinada superfície da referência, geralmente o nível médio do mar (IBGE, 1999).

Quanto à representação da bacia hidrográfica e seu estudo justifica-se pelo fato de apresentar-se como uma unidade espacial de aceitação universal. De acordo com Guerra $(2003$, p. 48) a bacia hidrográfica constitui-se em sistema natural por que é "composto por um conjunto de terras drenadas por um rio principal e seus afluentes" e também porque as interações podem ser interpretadas pelo input e output dos fluxos de matérias e energias.

As bacias hidrográficas são tratadas como unidades físicas importantes para o planejamento e desenvolvimento regional, pois constituem a unidade geográfica espacial que integra a relação do homem e a natureza (Zacharias, 2008). Destaca-se ainda, que as mesmas são de fácil reconhecimento e caracterização o que facilitará a compreensão dos alunos quando da apresentação do objeto de aprendizagem.

Após, a verificação dos conceitos a serem utilizados, iniciou-se o processo de elaboração dos objetos. Para tanto, foram necessários uma imagem de satélite do Google Earth, uma imagem Shuttle Radar Topography Mission (SRTM) no qual foram extraídas as curvas de nível, a rede de drenagem e os divisores de água. Este processo deu-se por meio do auxílio do aplicativo ArcGis 9.3 no módulo ArcMap.

A segunda parte constou da edição destes aspectos de modo interativo. Por meio dos softwares Photoshop e Flash foi possível criar a animação e os detalhes referentes aos aspectos da bacia hidrográfica e do relevo. Nesta elaboração atentou-se para que os mesmos pudessem favorecer a interação dos alunos com os materiais de modo que houvesse a construção do conhecimento, ou seja, ao interagir com o objeto os alunos poderão desenvolver novas percepções de espaço e identificar os aspectos geográficos que compõem o referido ambiente.

Destaca-se ainda, que o propósito dos objetos é permitir aos educandos a concepção de uma bacia hidrográfica e do relevo. Desta maneira, selecionou-se uma pequena área em que podem ser visualizados a imagem de satélite, o relevo, as curvas de nível, os divisores de água e os rios formando-se juntamente com a água da chuva. A visualização no modo 3D permite identificar as feições do relevo com maior facilidade e com isto, visualizar os divisores de água, os leitos dos rios, as nascentes e a jusante, os talvegues, as curvas de nível e outros elementos de acordo com a exploração que o professor fará ao apresentar o material aos seus alunos.

\section{RESULTADOS E DISCUSSÃO}

Estes objetos foram desenvolvidos para serem utilizados em processadores que suportem a interação com a Internet, pois possibilitam que os alunos interatuem com os mesmos, adicionando ou retirando aspectos que desejam visualizar. Os objetos de aprendizagem estão disponíveis para acesso e utilização no seguinte link: 
http://www.ufsm.br/cartografia/index.php?option=com_content\&view=category\&id=1 \&Itemid=7.

A idéia da elaboração e aplicação destes objetos deu-se com base em observações e em práticas de monitoria e docência orientada no curso de Geografia da Universidade Federal de Santa Maria, no qual se constatou dificuldades dos alunos na compreensão dos temas relacionados ao relevo e as bacias hidrográficas. Assim, inicialmente estes objetos foram utilizados nas aulas de cartografia, nos primeiros semestres do curso, visando melhorar a compreensão e entendimento destes temas pelos alunos. Os resultados mostraram-se positivos e a compreensão destes temas foi alcançada.

Sabe-se que muitas das dificuldades encontradas pelos alunos no ensino superior possuem suas origens na Educação Básica. Neste sentido, objetiva-se aplicar estes objetos a alunos do Ensino Fundamental a fins de validar o uso destes e de contribuir para uma aprendizagem significativa, procurando diminuir as lacunas existentes na aprendizagem de temas geográficos.

$\mathrm{O}$ processo de ensino e aprendizagem deve ser interativo e atender as necessidades dos próprios alunos, frente a sua realidade. Esta proposta de objetos de aprendizagem de forma lúdica e interativa visa, sobretudo, contemplar a compreensão dos elementos geográficos que são estudados no terceiro e quarto ciclos do Ensino Fundamental.

A proposta apresentada pode variar de acordo com o professor, em que inicialmente introduzirá o conteúdo a ser abordado, e num segundo momento permitirá que o próprio aluno visualize os aspectos da maneira que melhor compreender. A idéia não é deixar um roteiro de como trabalhar com estes materiais, mas sim, permitir que haja novas possibilidades de ensinar um conteúdo de modo dinâmico no qual o aluno consiga compreender alguns elementos que compõem o espaço em que está inserido com maior motivação e interesse.

\subsection{Simulador do Relevo}

O objeto de aprendizagem abordando o conceito de relevo foi denominado de Simulador do Relevo. Representa em três dimensões, uma imagem de satélite (aspecto real da superfície), as curvas de nível (linhas imaginárias) definidas sobre o relevo de 20 em 20 metros e seus respectivos valores, referenciados a partir do nível médio dos mares (Figura 1).

O material apresenta a área de estudo selecionada e em seu lado esquerdo, as opções de movimentação e visualização da mesma. Esta movimentação é muito importante, pois, permite conduzir ao aluno a idéia de continuidade do espaço e não somente de uma área restrita, ou seja, de algo descontínuo. Além disso, permite visualizar a área em várias posições, o que é fundamental para compreender a disposição dos elementos na superfície terrestre.

Observando-se a figura 1 (A) pode-se verificar e observar na imagem vários elementos que compõem o espaço e que com o passar do tempo podem influenciar nas formas do relevo. Já, na figura 1 (B) podem ser visualizadas as curvas de nível sobre o relevo, diferenciando notadamente as áreas mais elevadas, com vegetação, das planas, onde há ocupação humana. E por último, na figura 1 (C) são visualizados os valores referentes às curvas mestras ou principais, com base no nível médio dos mares. Assim, 
neste momento cabe ao professor guiar o trabalho a partir da introdução deste material. Existem várias possibilidades de exploração do mesmo e de interação do aluno.

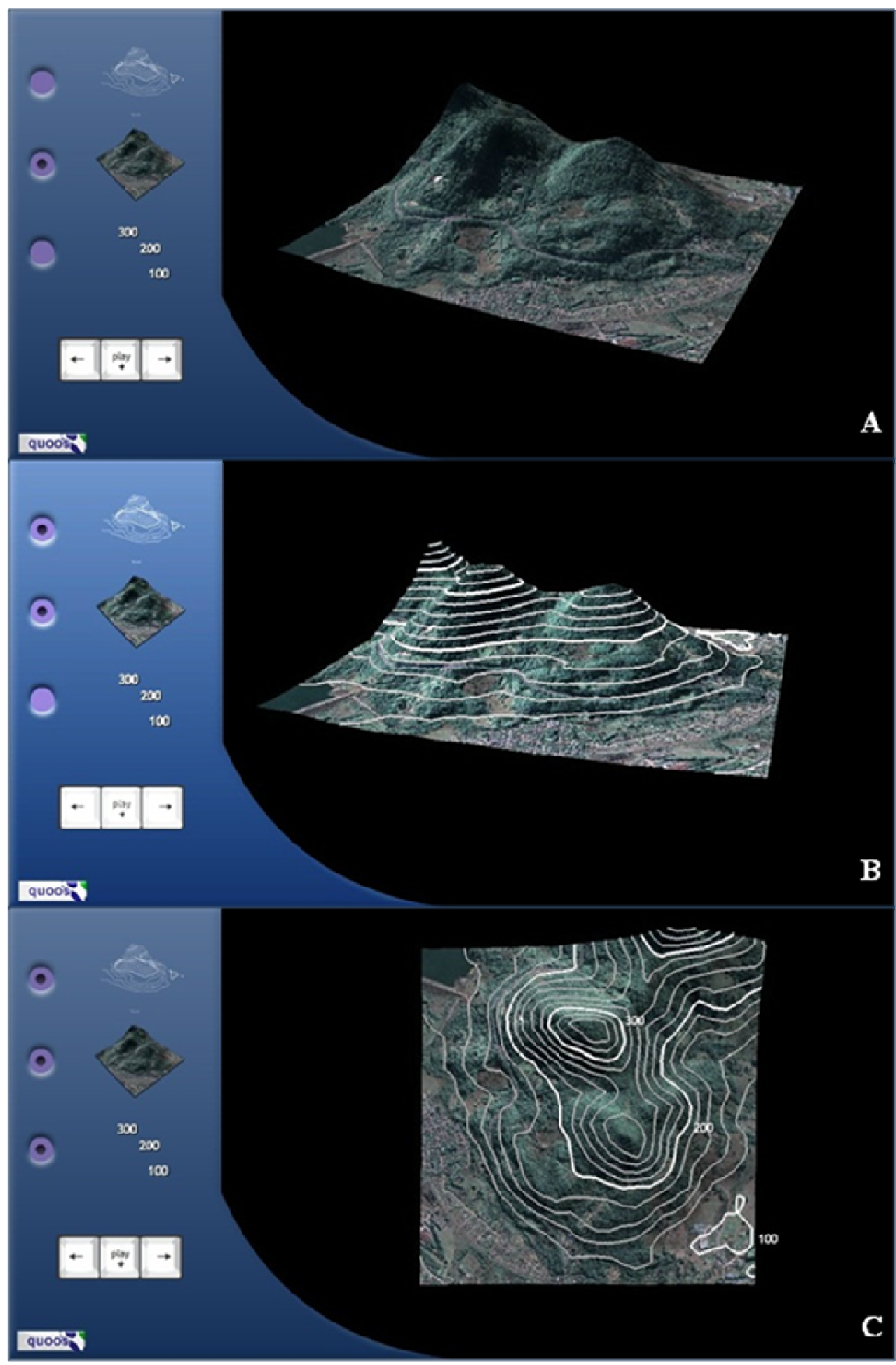

Figura 1 - Simulador do Relevo: visualização da imagem de satélite do Google Earth (A), visualização das curvas de nível (B) e valores das curvas de nível (C). 


\subsection{Simulador de Bacia Hidrográfica}

O objeto de aprendizagem referente ao estudo das bacias hidrográficas denominou-se Simulador de Bacia Hidrográfica (Figura 2). Seu funcionamento e apresentação são similares ao Simulador do Relevo, e apresenta em seu lado esquerdo cinco opções de visualização, simultâneas ou não, além de contar com os botões de movimentação da área. 


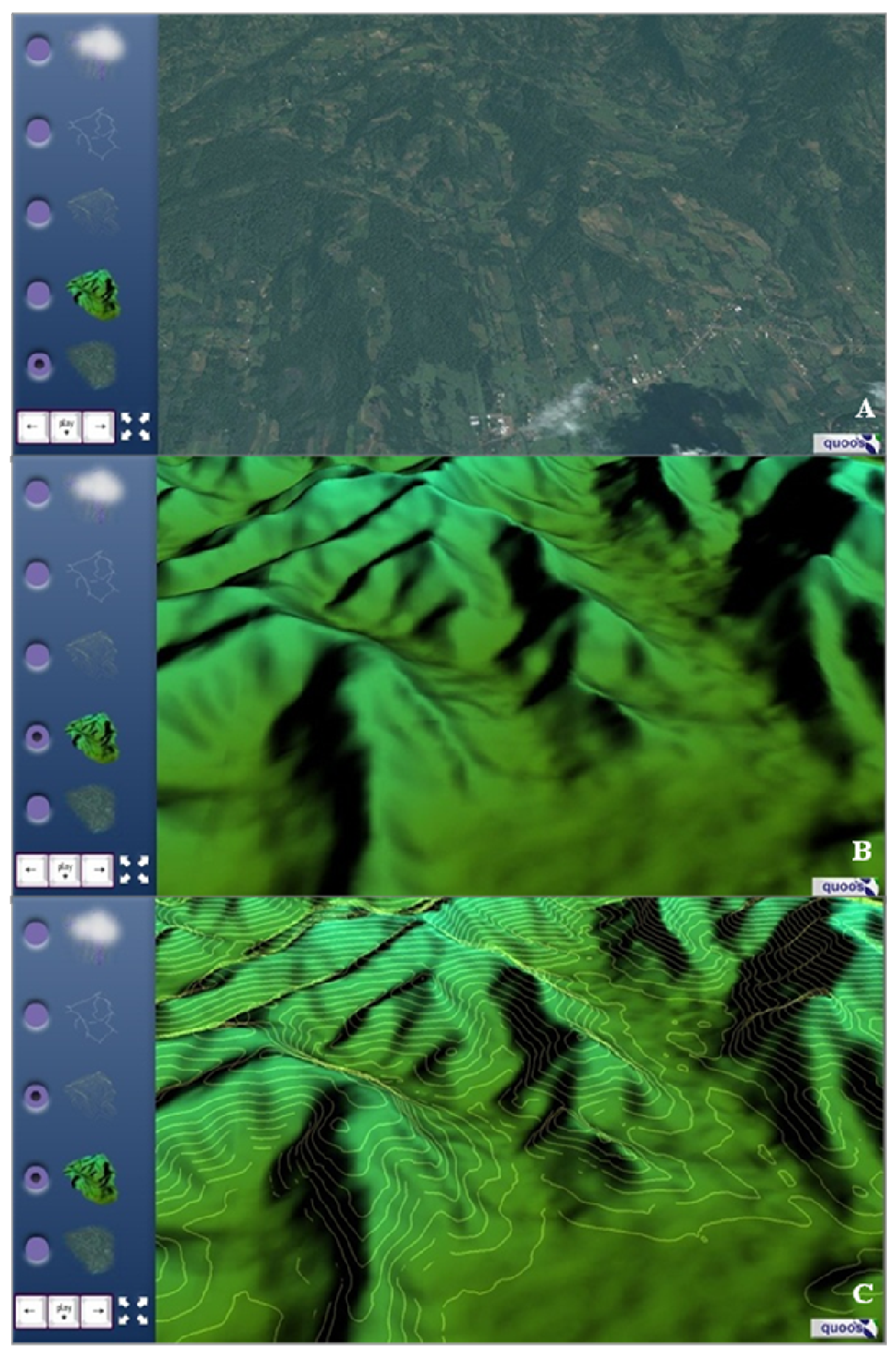

Figura 2 - Simulador da Bacia Hidrográfica: visualização da imagem de satélite do Google Earth (A), visualização da superfície (B) e visualização das curvas de nível (C). 
Inicialmente é necessário compreender o conceito de uma bacia hidrográfica e os inúmeros elementos que podem ser identificados no seu interior. Assim, uma bacia hidrográfica pode ser compreendida como um conjunto de terras drenadas por um rio principal e seus afluentes, resultante da reunião de dois ou mais vales, formando uma depressão no terreno, rodeada geralmente por elevações. Uma bacia se limita com outra pelo divisor de águas. Cabe ressaltar que esses limites não são fixos, deslocando-se em consequiência das mutações sofridas pelo relevo (IBGE, 1999).

Observando-se a figura 2 (A) pode-se visualizar uma imagem de satélite de uma determinada área. Nesta apresentação podem ser explorados diversos elementos presentes na visualização, como por exemplo: área povoada, campos, florestas, solo exposto, lugares mais altos e mais baixos. Enfim, a exploração nesta primeira visualização varia de acordo com a imaginação do professor e com a interação dos alunos.

Na figura 2 (B) observa-se a superfície do relevo. Esta visualização possibilita a exploração das noções de áreas fazendo uma ligação com a imagem anterior. $\mathrm{O}$ professor poderá fazer questionamentos aos seus alunos, como: Quais são as áreas mais elevadas e as menos elevadas? O que há em cada uma delas? O que as identifica como mais ou menos elevadas? Que cores são estas? Em que porção destas o rio nasce? Qual será a sua direção?

$\mathrm{Na}$ figura 2 (C) visualiza-se as curvas de nível sobre o relevo. È importante, neste momento, que o professor destaque a diferença entre o espaço das curvas de nível e sua visualização no terreno.

Após a visualização da imagem, da superfície do relevo e das curvas de nível, serão apresentados outros elementos importantes que constituem uma bacia hidrográfica. A figura 3 apresenta os divisores de água (A), os rios e a chuva (B) e a visualização geral dos elementos que compõem uma bacia $(\mathrm{C})$.

Na figura 3 (A) podem ser visualizados os divisores de água, que de acordo com IBGE (1999) materializam-se no terreno pela linha que passa pelos pontos mais elevados do terreno e ao longo do perfil mais alto entre eles, dividindo as águas de um e outro curso d'água. São definidos assim, pela linha de cumeeira que separa as bacias. Ao compreender esta visualização os alunos serão capazes de perceber qual será o curso do rio e sua direção.

A visualização dos rios e da chuva pode ser verificada na figura 3 (B). O movimento da chuva e seu posterior escoamento, formando o leito dos rios, são de suma importância para a compreensão da formação de uma bacia. A chuva em contato com solo seguirá uma direção, a partir dos divisores de água, e irá escorrer com maior ou menor intensidade (dependendo das formas do relevo) para um determinado curso. Este curso de água natural estende-se desde os pontos mais altos (nascente ou montante) até o ponto mais baixo (foz ou jusante) desaguando em outro rio, lago ou mar.

Além disso, é importante ter claramente o conceito de rio, que segundo IBGE (1999), é um curso d'água natural que deságua em outro rio, lago ou mar. Os rios levam as águas superficiais, realizando uma função de drenagem, ou seja, o escoamento das águas. Seus cursos estendem-se do ponto mais alto (nascente ou montante) até o ponto mais baixo (foz ou jusante), que pode corresponder ao nível do mar, de um lago ou de outro rio do qual é afluente. 
Na última visualização é possível verificar todos os elementos que compõem uma bacia simultaneamente (Figura 3 - C). Esta visualização apresenta a disposição dos elementos estudados sobre a imagem de satélite.

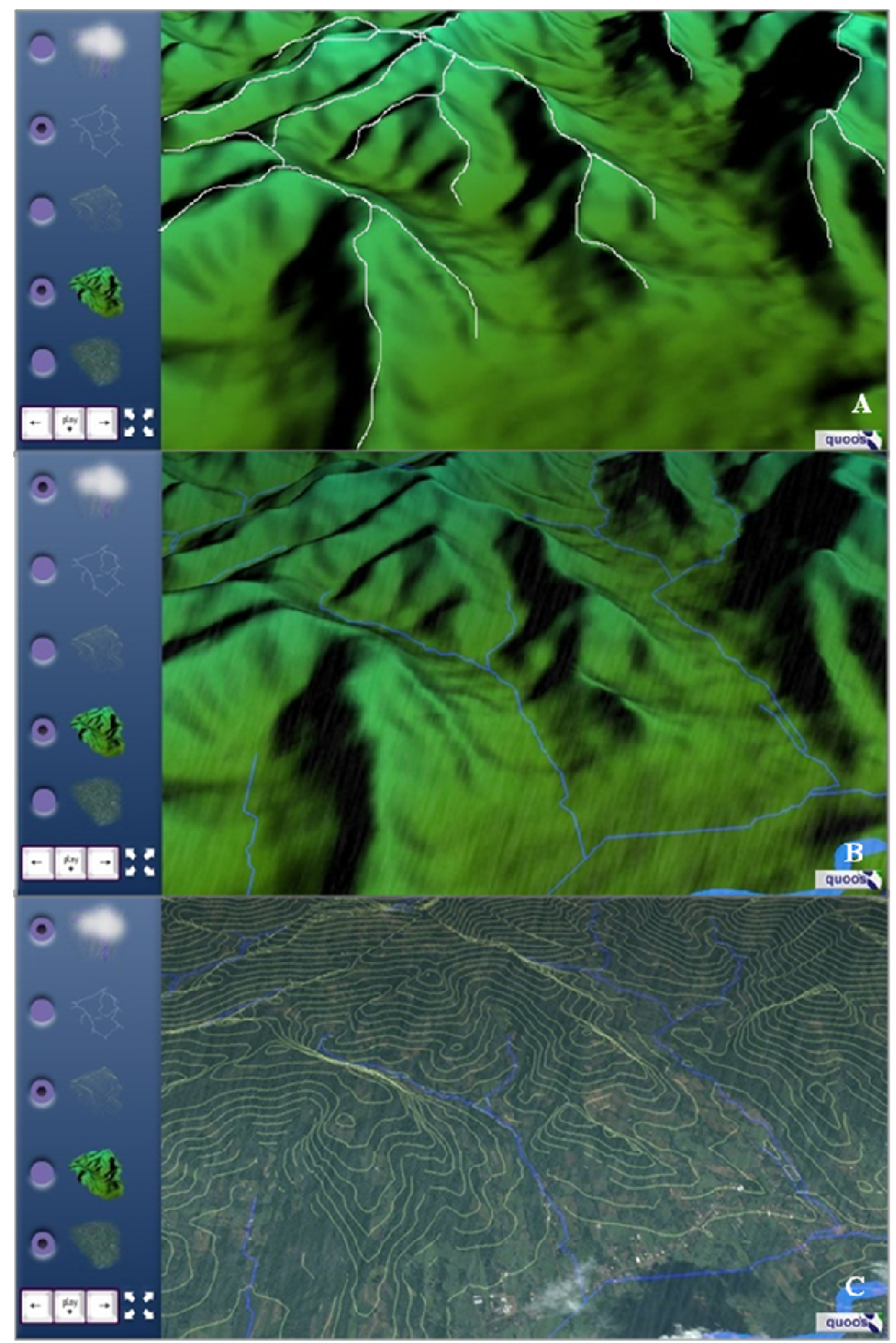

V. $10 \mathrm{~N}^{\mathrm{o}} 1$, julho, 2012 
Figura 3 - Simulador da Bacia Hidrográfica: visualização dos divisores de água (A), visualização dos rios e da chuva (B) e visualização geral dos elementos que compõem uma bacia hidrográfica $(\mathrm{C})$.

Com base nesta visualização, pode-se inferir que os alunos sejam capazes de identificar os componentes de uma bacia hidrográfica e relatar como ocorre a sua formação, interagindo com seus colegas. A troca de saberes é fundamental em um processo de ensino e aprendizagem.

É importante salientar que a sequência de visualização dos elementos pode ser inicialmente introduzida pelo professor e posteriormente pelos alunos, de acordo com seu entendimento. A exploração do recurso não se restringe somente a visualização dos elementos apresentados podendo avançar em termos teóricos. A partir deste objeto, o professor poderá impulsionar seus alunos para que desenvolvam o senso crítico e avancem em pesquisas sobre as riquezas naturais do Brasil e sua exploração.

Ao abordar os conceitos citados e apresentá-los visualmente aos alunos, o professor necessitará considerar a diversidade de bens naturais que neles se encontram. Ao entendermos uma bacia, como um sistema aberto, condicionada pelas formas do relevo, necessariamente devemos abordar as dimensões físico, química e biológica, dimensões econômica, político-institucional e social em que se localizam. É muito importante que os alunos percebam estas dimensões em nível local, ou seja, no espaço que estão inseridos. Assim, estaremos contribuindo para que sejam críticos com o próprio sistema em que vivem.

Destaca-se ainda, a importância da aplicação deste material como recurso inovador em sala de aula. O processo sócio-educativo deve caminhar ao encontro de recursos que estimulem a participação dos alunos e integre sua realidade. Há uma grande necessidade de inovar em sala de aula para obter melhores resultados quanto ao ensino e a aprendizagem.

\section{CONCLUSÕES}

O processo de ensino e aprendizagem, especialmente de temas geográficos, pode ser favorecido por meio de objetos de aprendizagem interativos e inovadores que permitam aos alunos construir o seu próprio conhecimento. Os temas geográficos estudados em sala de aula podem ser melhor compreendidos quando o professor busca inovar, por meio de novas técnicas, e procura interagir com seus alunos de modo que haja uma participação efetiva dos mesmos.

Os objetos de aprendizagem abordados neste trabalho, simulador do relevo e simulador de bacias hidrográficas, são recursos didáticos importantes na percepção do espaço pelos alunos. Esta percepção, juntamente com a noção de tempo, possibilita ao aluno visualizar a dinâmica espacial e fazer parte do processo de construção de um meio mais organizado e equilibrado.

A elaboração de objetos de aprendizagem e sua aplicação no meio escolar apresentam-se como uma nova meta a ser atingida de maneira igualitária, possibilitando a inclusão de muitos educandos neste processo tão importante de ensino e aprendizagem de modo interativo. $\mathrm{O}$ contato do aluno com a sua realidade, ou o mais próximo que seja, permitirá a construção de seu mundo real e uma visão crítica do ambiente em que vive. 


\section{REFERÊNCIAS BIBIOGRÁFICAS}

BARROS, D. M. V.; JUNIOR, W. A. Objetos de aprendizagem virtuais: material didático para a educação básica. Net, 2005. Disponível em: < http://www.abed.org.br/congresso2005/por/pdf/006tcc1.pdf>. Acesso em: 10 maio 2012.

BITAR, J. C. M.; SOUSA, C. L. de. A geografia e o uso da linguagem cartográfica na educação básica. In: IX CONGRESSO NACIONAL DE EDUCAÇÃO. 2009, Paraná. Anais eletrônicos... Paraná, 2009. Disponível em: < www.pucpr.br/eventos/educere/educere2009/anais/pdf/2290_1356.pdf >. Acesso em: 23 jun. 2011.

GIORDANI, A. C.; BEZZI, M. L.; CASSOL, R. Contribuição para a alfabetização cartográfica através do objeto de aprendizagem decifrando os mapas. Novas Tecnologias na Educação. Porto Alegre, v. 6, n. 1, p. 1-10, jul. 2008.

GUERRA, A. T. Dicionário Geológico e Geomorfológico. $8^{\mathrm{a}}$ Ed. Rio de Janeiro: IBGE. 1993. 48 p.

IBGE. Noções Básicas de Cartografia. Rio de Janeiro: IBGE. 1999. Disponível em: <http://www.ibge.gov.br/home/geociencias/cartografia/manual_nocoes/indice.htm>. Acesso em: 20 jul. 2011.

MOREIRA, S. A. G.; ULHÔA, L. M. Ensino em Geografia: desafios à prática docente na atualidade. Net, Uberlândia, 2009. Disponível em: < http://www.catolicaonline.com.br/revistadacatolica/artigosv1n2/06-GEOGRAFIA01.pdf>. Acesso em: 11 maio 2012.

Parâmetros Curriculares Nacionais - PCNs. Brasília: MEC, 1998.

SALES, M. V. S. As tecnologias, o ensino e a formação do(a) professor(a) de Geografia: novas linguagens na transformação da prática. In: 10 $^{\circ}$ ENCONTRO NACIONAL DE PRÁTICA DE ENSINO EM GEOGRAFIA. 2009. Porto Alegre. Anais. Porto Alegre: Universidade Federal do Rio Grande do Sul, 2009. p. 1 - 17

SANTOS, M. Técnica, espaço e tempo: globalização e meio técnico-científicoinformacional. São Paulo: Hucitec, 1994.

TAROUCO, L. M. R.; FABRE, M. C. J. M.; TAMUSIUNAS, F. R. Reusabilidade de objetos educacionais. Net, Porto Alegre, fev. 2003. Disponível em: <http://seer.ufrgs.br/renote/article/view/13628/7697>. Acesso em: 11 maio 2012.

ZACHARIAS, A. A. As categorias de análise da Cartografia no mapeamento e Síntese da paisagem. Revista Geografia e Pesquisa. Ourinhos, v. 2, n. 1, p. 33-56, 2008. 